\title{
Aplikasi Pewarnaan Graf dengan Algoritma Recursive Largest First pada Penjadwalan Mata Kuliah
}

\author{
Rahmat Syam ${ }^{1}$, Hisyam Ihsan ${ }^{1}$, dan Asman ${ }^{1, \text { a) }}$ \\ ${ }^{1}$ Jurusan Matematika, Fakultas Matematika dan Ilmu Pengetahuan Alam \\ Universitas Negeri Makassar \\ a)asmanrc45@gmail.com
}

\begin{abstract}
Abstrak. Penelitian ini merupakan penelitian terapan yang menggunakan algoritma Recursive Largest First (RLF) pada penjadwalan mata kuliah di salah satu program studi pada salah satu universitas di Makassar. Penjadwalan mata kuliah dilakukan dengan merepresentasikan masalah ke dalam bentuk graf berdasarkan data yang diperoleh dengan menganggap mata kuliah sebagai simpul dan dosen sebagai sisi. Dibentuk matriks ketetanggaan dari graf yang terbentuk, kemudian simpulya diwarnai menggunakan algoritma RLF, sehingga diperoleh jadwal kuliah. Penjadwalan mata kuliah menggunakan pewarnaan simpul graf dengan algoritma RLF digunakan VBA for Microsoft Excel 2016 sebagai alat bantu dalam pewarnaan simpul graf. Diperoleh 102 simpul dengan 25 warna yang menunjukkan bahwa dibutuhkan 25 waktu perkuliahan. Jumlah simpul yang diwarnai dengan warna yang sama $\leq 6$ simpul artinya dalam setiap slot dibutuhkan maksimal 6 ruangan perkuliahan. Mata kuliah yang terjadwal dijamin bahwa tidak ada jadwal dosen yang bersamaan untuk setiap mata kuliah yang diajarkan.
\end{abstract}

Kata Kunci: Graf, Recursive Largest First, Jadwal Kuliah

\begin{abstract}
This research discusses the colorization of graph vertex using algorithm of Recursive Largest First (RLF) in scheduling courses in one of the study programs at one of the universities in Makassar. Representation of problems in scheduling courses was done by making it in the shape of the graph assuming subjects as vertex and the presence of the same lecturers teach different courses as a side. The steps in solving a problem that was mapping the lectures data, representing the lectures data as a graph, forming adjacency matrix, coloring the graph vertex using algorithm of $R L F$, so that the schedule was retrieved. Scheduling of courses using the colorization of graph vertex with algorithm of RLF as well as the help of VBA for Microsoft Excel 2016 at Faculty of Animal Husbandry obtained 102 vertices with 25 colors indicates that it takes 25 of lecture schedules. The number of vertices that were colored with the same color $\leq 6$ vertices meaning in every slot needed 6 lecture rooms in maximum. Scheduled courses are guaranteed that no schedule conflicts for each lecturer of courses taught.
\end{abstract}

Keywords: Graph, Recursive Largest First, Lecture Schedules.

\section{PENDAHULUAN}

Penjadwalan kegiatan sangat dibutuhkan untuk menjalankan aktivitas sehari-hari agar setiap kegiatan dapat dijalankan sesuai waktunya. Penjadwalan merupakan kegiatan yang dilakukan untuk mengalokasikan sumber-sumber yang ada untuk menjalankan sekumpulan tugas dalam jangka waktu tertentu (Sunarni, Bendi, \& Alfian, 2017). Penyusunan jadwal kuliah merupakan masalah yang sering dihadapi oleh sebagian besar universitas hampir di seluruh dunia. Ada banyak faktor sehingga terjadi bentrokan dalam menyusun jadwal kuliah. Faktor-faktor tersebut 
dapat berupa berbagai kepentingan yang berbeda tiap orang dengan lokasi yang berbeda pada waktu yang bersamaan (Sari, Rachmawati, \& Akbar, 2013).

Topik mengenai masalah penjadwalan telah banyak dibahas dalam berbagai penelitian (Hiryanto \& Thio, 2011; Sari, Rachmawati, \& Akbar, 2013; Harianto \& Fathda, 2015; Hidayatulloh, 2015; Mahardika \& Marcos, 2017; Sunarni, Bendi, \& Alfian, 2017). Hasil yang diperoleh menunjukkan bahwa teknik pewarnaan simpul graf dapat menyelesaikan masalah penjadwalan sehingga tidak ditemukan jadwal yang tumpang tindih waktu pelaksanaannya. Salah satu cara untuk menyelesakan masalah penjadwalan secara optimal adalah menerapkan berbagai metode-metode penjadwalan yang telah dikembangkan sebelumnya seperti metode berbasis populasi, metode heuristik, dan metode pewarnaan simpul graf.

Pewarnaan simpul graf menempatkan kejadian demi kejadian secara sekuensial ke dalam periode waktu yang valid sedemikian sehingga tidak ada konflik antar kejadian. Teknik ini menggunakan representasi graf, di mana kejadian direpresentasikan sebagai verteks dan konflik direpresentasikan sebagai jalur/simpul (Sunarni, Bendi, \& Alfian, 2017). Hasil telaah literatur menunujukkan algoritma Recursive Largest First mempunyai keunggulan yang mampu mengatasi penjadwalan dengan graf yang berorde besar.

Oleh karena itu, penelitian ini menerapkan teknik pewarnaan simpul graf dengan algoritma Recursive Largest First dalam menyelesaikan penjadwalan mata kuliah. Teknik ini digunakan agar tidak ditemukannya lagi jadwal perkuliahan yang tumpang tindih.

\section{KAJIAN PUSTAKA}

\section{Graf}

\section{Definisi 1}

Graf merupakan struktur diskrit yang terdiri atas dua himpunan, yakni himpunan simpul (vertex) dan himpunan sisi (edge), biasa dinotasikan $\mathrm{G}(\mathrm{V}, \mathrm{E})$.

(Adiwijaya, 2016)

Notasi sebuah graf adalah $\mathrm{G}=(\mathrm{V}, \mathrm{E})$, di mana:

1. V merupakan himpunan tak kosong dari simpul-simpul, misalkan $\mathrm{V}=\{\mathrm{v} 1, \mathrm{v} 2, \ldots, \mathrm{vn}\}$.

2. E merupakan himpunan sisi-sisi yang menghubungkan sepasang simpul, misalkan $E=\{e 1$, $\mathrm{e} 2, \ldots, \mathrm{en}\}$.

Gambar 1 merupakan salah satu contoh graf, yakni graf $\mathrm{G}$ dengan $\mathrm{V}=\{\mathrm{v} 1, \mathrm{v} 2, \mathrm{v} 3, \mathrm{v} 4\}$ dan $\mathrm{E}=\{\mathrm{e} 1$, $\mathrm{e} 2, \mathrm{e} 3, \mathrm{e} 4, \mathrm{e} 5\}$.

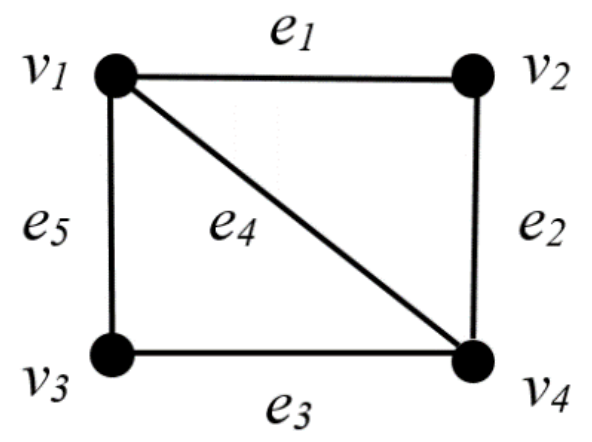

GAMBAR 1. Graf G 
Definisi 2

Derajat suatu simpul pada graf tak berarah adalah jumlah sisi yang bersisian dengan simpul tersebut. Notasi: d(v) menyatakan derajat simpul v.

(Munir, 2003)

\section{Representasi Graf}

Graf dapat direpresentasikan dengan mendaftar himpunan simpul dan himpunan sisinya. Cara lain untuk merepresentasikan suatu graf adalah sebagai berikut (Sudirman, 2013):

1. Daftar ketetanggaan.

Daftar ketetanggaan yaitu menentukan simpul-simpul yang bertetangga dengan setiap simpul pada graf.

2. Matriks ketetanggaan

Definisi 3

Sebarang graf $\mathrm{G}$ berkorespondensi dengan suatu matriks berukuran nxn yang disebut matriks ketetanggaan dari $\mathrm{G}$. Matriks ketetanggaan $\mathrm{A}(\mathrm{G})=\left[a_{i j}\right]$, dimana $a_{i j}$ adalah banyak sisi yang terkait dengan simpul $v_{i}$ dan $v_{j}$. (Muktyas, 2010)

$$
a_{i j}=\left\{\begin{array}{l}
1, \text { jika }\left(v_{i}, v_{j}\right) \in E \\
0, \text { jika selainnya }
\end{array}\right.
$$

Persamaan (1) menjelaskan bahwa $a_{i j}=1$ jika $v_{i}$ bertetangga dengan $v_{j}$ atau simpul 1 saling berhubungan dengan simpul 2 (Sari, Rachmawati, \& Akbar, 2013).

\section{Pewarnaan Graf}

Pewarnaan graf adalah metode pewarnaan elemen dari sebuah graf yang terdiri dari pewarnaan simpul (vertex), sisi (edge), dan wilayah (region).

\section{Definisi 4}

Pewarnaan simpul pada graf adalah memberi warna pada simpul-simpul suatu graf sehingga tidak ada dua simpul yang bertetangga memiliki warna yang sama. Simpul-simpul dapat diberikan sembarang warna asalkan simpul tetangganya berbeda.

(Munir, 2003)

Bilangan kromatik graf $\mathrm{G}$ adalah minimum banyaknya warna yang diperlukan untuk mewarnai semua simpul G, sedemikian sehingga setiap dua simpul yang berhubungan langsung mendapat warna yang berbeda. Bilangan kromatik dari graf $\mathrm{G}$ dilambangkan dengan $\chi(\mathrm{G})$ yang didefinisikan sebagaimana persamaan (2).

$$
\chi(\mathrm{G})=\min \{\mathrm{k} \mid \text { ada pewarnaan-k pada } \mathrm{G}\}
$$

Suatu pewarnaan simpul graf dikatakan efektif jika pewarnaan simpul graf tersebut memenuhi definisi 4. Suatu pewarnaan simpul graf disebut efisien jika jumlah warna yang digunakan untuk mewarnai suatu graf adalah bilangan kromatik dari graf tersebut (Sudirman, 2013). 
A

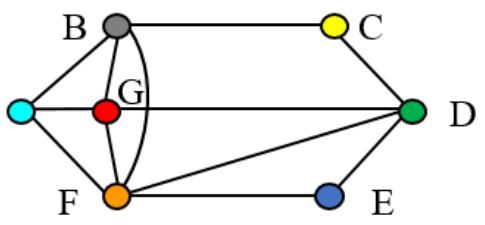

(a)
A

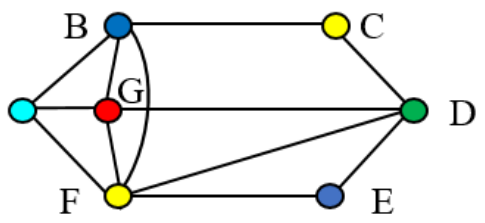

(b)

A

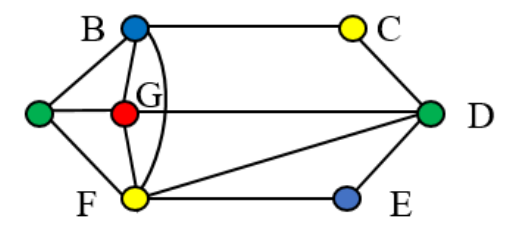

(c)

GAMBAR 2. Graf G dengan berbagai warna; (a) 7 warna, (b) 5 warna, (c) 4 warna.

Gambar 2 menunjukkan graf $G$ dengan berbagai warna antara lain 7 warna, 5 warna, dan 4 warna. Namun, tidak bisa diwarnai dengan jumlah warna kurang dari 4 warna karena ketika graf $G$ diwarnai dengan 3 warna akan terdapat dua simpul yang bertetangga memiliki warna yang sama. Hal tersebut bertentangan dengan definisi pewarnaan simpul. Jadi, bilangan kromatik pada graf $\mathrm{G}$ adalah 4 , ditulis $\chi(\mathrm{G})=4$.

\section{Algoritma Recursive Largest First}

Algoritma Recursive Largest First (RLF) merupakan salah satu algoritma yang dapat digunakan dalam pewarnaan graf untuk menyelesaikan suatu permasalahan. Algoritma RLF mampu mengatasi penjadwalan dengan graf yang berorde besar. Langkah-langkah dari algoritma RLF yaitu mendaftar semua derajat simpul dan mengurutkannya secara descending. Dipilih simpul yang berderajat terbesar sebagai simpul awal dan diwarnai dengan sebuah warna. Dicari simpul yang tidak bertetangga dengan simpul awal sehingga simpul-simpul tersebut menjadi calon simpul yang akan diwarnai sama dengan simpul awal. Diseleksi calon simpul sehingga diperoleh simpul mana saja yang dapat diwarnai sama dengan warna simpul awal. Langkah-langkah di atas diulang hingga semua simpul terwarnai (Sari, Rachmawati, \& Akbar, 2013).

\section{METODE PENELITIAN}

Penelitian ini adalah penelitian terapan yang bertujuan untuk menyelesaikan masalah penjadwalan mata kuliah menggunakan/menerapkan pewarnaan graf dengan algoritma Recursive Largest First. Langkah-langkah penyelesaian masalah yang dilakukan dalam penelitian ini yaitu mengumpulkan data perkuliahan berupa daftar mata kuliah, dosen, ruangan, dan waktu perkuliahan yang diperoleh dari salah satu program studi pada salah satu universitas yang ada di Makassar. Data perkuliahan dipetakan ke dalam bentuk tabel pembebanan yang berupa tabel hubungan antara mata kuliah dan dosen yang mengajar mata kuliah tersebut. Hasil pemetaan data perkuliahan direpresentasikan sebagai suatu graf yang menghasilkan matriks ketetanggaan. Berdasarkan matriks ketetanggaan yang dihasilkan, dilakukan pewarnaan graf menggunakan algoritma Recursive Largest First. Untuk memudahkan dalam penelitian ini digunakan VBA for Microsoft Excel 2016 sebagai alat bantu dalam menghasilkan jadwal mata kuliah. 


\section{HASIL DAN PEMBAHASAN}

Pemetaan data perkuliahan yakni hubungan antara mata kuliah dengan dosen dalam bentuk tabel pembebanan, dapat dilihat pada Tabel 1. MK-01, MK-02, MK-03, MK-04, MK-05, MK-06, dan MK-07 merupakan kode tiap mata kuliah. D1, D2, D3, D4, D5, dan D6 merupakan kode dosen.

Tabel 1 merupakan tabel pembebanan masalah penjadwalan mata kuliah. Mata kuliah MK-01 diajar oleh dosen D1 dan D4 sehingga semua mata kuliah yang diajarkan oleh dosen D1 atau D4 dikatakan berhubungan langsung dengan MK-01 yang ditandai adanya sisi yang menghubungkan simpul-simpul tersebut. Mata kuliah yang diajar oleh dosen D1 selain MK-01 yaitu MK-03, MK06, dan MK-07. Mata kuliah yang diajar oleh dosen D4 selain MK-01 yaitu MK-02. Sehingga MK-01 berhubungan langsung (bertetangga) dengan MK-02, MK-03, MK-06, dan MK-07. Dengan cara yang sama untuk mencari simpul-simpul tetangga dari MK-02, Mk-03, MK-04, MK05, MK-06, dan MK-07. Simpul v1 mewakili MK-01, v2 mewakili MK-02, v3 mewakili MK-03, v4 mewakili MK-04, v5 mewakili MK-05, v6 mewakili MK-06, dan v7 mewakili MK-07.

TABEL 1. Tabel Pembebanan

\begin{tabular}{|c|c|c|c|c|c|c|}
\hline & D1 & D2 & D3 & D4 & D5 & D6 \\
\hline MK-01 & & & & & & \\
\hline MK-02 & & & & & & \\
\hline MK-03 & & & & & & \\
\hline MK-04 & & & & & & \\
\hline MK-05 & & & & & & \\
\hline MK-06 & & & & & & \\
\cline { 1 - 4 } MK-07 & & & & & \\
\hline
\end{tabular}

Representasi tabel 1 ke dalam graf $\mathrm{G}$ dapat dilihat pada gambar 3 .

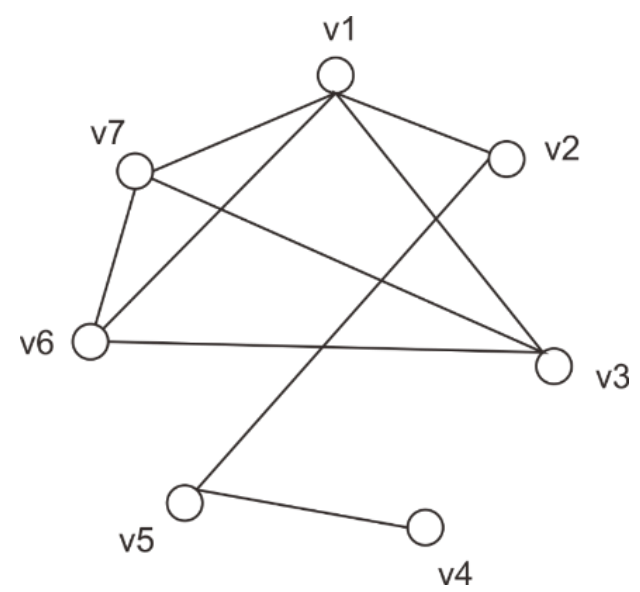

GAMBAR 3. Graf G Representasi Tabel Pembebanan. 
Graf G kemudian diwarnai simpulnya dengan algoritma RLF sehingga diperoleh hasil pewarnaan graf yang terlihat pada gambar 4. Hasil pewarnaan simpul graf menggunakan bantuan VBA for Microsoft Excel 2016 dapat dilihat pada tabel 2.

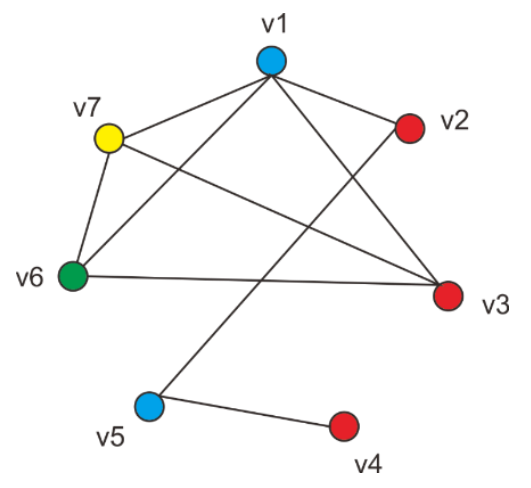

GAMBAR 4. Graf G Setelah Diwarnai dengan Algoritma RLF

TABEL 2. Hasil Jadwal Mata Kuliah dengan Bantuan VBA for Micosoft Excel 2016

\begin{tabular}{lccccc}
\hline \multirow{2}{*}{ Mata Kuliah } & \multirow{2}{*}{ Ruangan } & \multicolumn{2}{c}{ Waktu } & \multirow{2}{*}{ Dosen } \\
\cline { 3 - 4 } MK-01 & R1 & Senin & $08.00-09.40$ & D01 & D04 \\
MK-02 & R2 & Senin & $10.00-11.40$ & D03 & D04 \\
MK-03 & R1 & Senin & $10.00-11.40$ & D01 & D06 \\
MK-04 & R3 & Senin & $10.00-11.40$ & D02 & D05 \\
MK-05 & R2 & Senin & $08.00-09.40$ & D03 & D05 \\
MK-06 & R1 & Senin & $13.00-14.40$ & D01 & D06 \\
MK-07 & R1 & Senin & $15.00-16.40$ & D01 & D06 \\
\hline
\end{tabular}

\section{KESIMPULAN}

Penjawalan mata kuliah menggunakan pewarnaan graf dengan algoritma RLF serta bantuan VBA for Microsoft Excel 2016 diperoleh 102 simpul dengan 25 warna yang menunjukkan bahwa dibutuhkan 25 waktu perkuliahan. Jumlah simpul yang diwarnai dengan warna yang sama $\leq 6$ simpul artinya dalam setiap slot dibutuhkan 6 ruangan perkuliahan. Mata kuliah yang terjadwal dijamin bahwa tidak ada jadwal dosen yang bersamaan untuk setiap mata kuliah yang diajarkan.

Proses penjawalan mata kuliah menggunakan pewarnaan graf dengan algoritma RLF dilakukan dengan program simulasi komputer untuk menghasilkan output yang lebih cepat. Hasil yang diperoleh secara manual dan menggunakan bantuan program komputer tidak memiliki perbedaan pada jumlah warna dan anggota kelompok tiap warna. Program ini juga menjamin bahwa tidak ada jadwal dosen yang mengajar beberapa mata kuliah akan mendapatkan jadwal yang bersamaan untuk setiap mata kuliah yang diajarkannya. Hal ini sesuai dengan definisi pewarnaan simpul graf.

Melalui penelitian ini diharapkan dapat menjadi masukkan dalam meningkatkan wawasan serta pengetahuan khususnya tentang teori graf. Pembahasan dalam penelitian ini berfokus pada 
variabel mata kuliah dan dosen. Penelitian selanjutnya diharapkan untuk memperhatikan variabel lain diantaranya mahasiswa yang memprogramkan mata kuliah. Selain itu, teknik pewarnaan simpul graf dapat juga dikembangkan menggunakan algoritma Welch-Powell, Backtracking, dan Greedy.

\section{DAFTAR PUSTAKA}

Adiwijaya. (2016). Matematika Diskrit dan Aplikasinya. Bandung: Alfabeta.

Harianto, K. \& Fathda, T. S. E. (2015). Penerapan Pewarnaan Simpul Graf Untuk Menentukan Jadwal Ujian Skripsi pada STMIK Amik Riau Menggunakan Algoritma Welch-Powell. Jurnal Sains dan Teknologi Informasi, 1(2). 48-54.

Hidayatulloh, T. (2015). Perancangan Sistem Penjadwalan Pembelajaran Graph Coloring. Jurnal INFORMATIKA, 2(2). 416-424.

Hiryanto, L. \& Thio, J. S. (2011). Pengembangan Metode Graph Coloring Untuk University Course Timetabling Problem pada Fakultas Teknologi Informasi Universitas Tarumanagara Jakarta. Jurnal Ilmu Komputer dan Informasi, 4(2).

Mahardika, F. \& Marcos, H. (2017). Penerapan Algoritma Graf Welvh Powel pada Penjadwalan Mata Kuliah dan Jadwal Asisten Study Kasus Forum Asisten STMIK AMIKOM Purwokerto. Jurnal SIMETRIS, 8(2). 825-832.

Muktyas, I. B. (2010). Program Pewarnaan Graf untuk Pemodelan Penjadwalan Ujian Semester di Jurusan Matematika UNNES (Skripsi). Universitas Negeri Semarang, Semarang.

Munir, R. (2003). Matematika Diskrit. Bandung: Informatika.

Sari, P. B., Rachmawati, H., \& Akbar, M. (2013). Pewarnaan Graph Untuk Penyusunan Jadwal Kuliah Menggunakan Algoritma Recursive Lerge First (Studi Kasus: Politeknik Caltex Riau). Jurnal Aksara Komputer Terapan Politeknik Caltex Riau, 2(2). 36-42.

Sudirman, E. (2013). Pewarnaan Simpul Graf Menggunakan Algoritma Welch-Powell dan Aplikasinya pada Penjadwalan Kuliah di Jurusan Matematika FMIPA UNM (Skripsi). Universitas Negeri Makassar, Makassar.

Sunarni, T., Bendi, K. J., \& Alfian, A. (2017). Optimasi Penjadwalan Mata Kuliah Menggunakan Pewarnaan Graf. Prosiding SNTI dan SATELIT (pp. E48-53). Malang, Indonesia: Jurusan Teknik Industri Universitas Brawijaya. 